\title{
A New Approach of Brown's Double Exponential Smoothing Method in Time Series Analysis
}

\author{
S. Hansun
}

\begin{abstract}
Double Exponential Smoothing is an improvement of Simple Exponential Smoothing, also known as Exponential Moving Average, which does the exponential filter process twice. It's usually been used to predict the future data in time series analysis, where there is a trend in the data. In this paper, we aim to introduce a new approach of Brown's Double Exponential Smoothing in time series analysis. The new approach will combine the calculation of weighting factor in Weighted Moving Average and implement the results with Brown's Double Exponential Smoothing method. The proposed method will be tested on Jakarta Stock Exchange (JKSE) composite index data. The result of the proposed method shows a promising result in this work.
\end{abstract}

Index Terms-Brown's Double Exponential Smoothing, JKSE composite index, time series analysis, Weighted Moving Average.

\section{INTRODUCTION}

A TIME SERIES is a set of regular time-ordered observations of a quantitative characteristic of an individual or collective phenomenon taken at successive, in most cases equidistant, periods or points of time [1]. Mainly, the usage of time series models can be divided into two, i.e. to obtain an understanding of the underlying forces and structures that produced the observed data, and to fit a model and proceed to forecasting, monitoring, or even feedback and forward control [2]. In order to understand the characteristics of a time series, many researchers have adopted and developed time series analysis methods with the final aim to find a pattern which can be used to forecast future event or data $[3,4,5]$.

One of time series method that has been used widely by people is the moving average method. Although many other soft computing methods have been developed recently, as we can find in the works of Stevenson and Porter [6], Hansun [7, 8], and Popoola $[9,10]$, the moving average method still considered as the best method by many people due to its easiness, objectiveness, robustness, and usefulness [11, 12].

There are various kinds of moving average methods, but their underlying purpose remain the same, that is to track the trend determination of the given time series data $[11,13]$.

S. HANSUN, is with Department of Computer Science Universitas Multimedia Nusantara, Tangerang, Indonesia, (e-mail: hansun@umn.ac.id).
The simplest type of moving average is Simple Moving Average (SMA), where each point in time series data is weighted the same, regardless of where it occurs in the sequence. Weighted Moving Average (WMA) is an improvement of SMA, which gives a weighting factor for each point in time series data. Another type of moving average is Exponential Moving Average (EMA) which actually is a variation of WMA that used exponential number as the basis in forming weighting factors in time series analysis.

Hansun had introduced a new approach of moving average method which combine the WMA and EMA methods to forecast the future data in a time series data [14]. In this research, we will further develop the hybrid method introduced by Hansun, by modifying and combining the WMA method with Brown's Double Exponential Smoothing method. The proposed method will be implemented on Jakarta Stock Exchange composite index data and be compared with other moving average methods.

\section{WeIGHTED MOVIng AVERAGE AND BROWN's DOUBle EXPONENTIAL SMOOTHING}

The proposed method in this research combines the Weighted Moving Average and Brown's Double Exponential Smoothing which is one of the well-known exponential smoothing methods in time series analysis.

\section{A. Weighted Moving Average (WMA)}

A Weighted Moving Average (WMA) is an improvement form of Simple Moving Average (SMA). It gives a greater weight to more recent data than the older ones. The weighting factors are calculated from the sum of days used in time series data, also known as the 'sum of digits' [12]. The formula used can be described as below, where $n$ refers to the period or span number of forecasting formula and $P_{m}$ refers to the value of time series data at point $m$ [15].

$$
W M A=\frac{n P_{m}+(n-1) P_{m-1}+\cdots+2 P_{(m-n+2)}+P_{(m-n+1)}}{n+(n-1)+\cdots+2+1}
$$

\section{B. Brown's Double Exponential Smoothing}

Brown's Double Exponential Smoothing, also known as Brown's Linear Exponential Smoothing, is one type of double exponential smoothing which uses two different smoothed 
series that are centered at different points in time [16]. The formula is based on an extrapolation of a line through the two centers and can be described as below [16]. Let $S^{\prime}$ denote the single-smoothed series obtained by applying simple exponential smoothing to series $Y$ and $S^{\prime \prime}$ denote the doublesmoothed series obtained by applying simple exponential smoothing (using the same constant smoothing factor, $\alpha$ ) to series $S^{\prime}$ :

$$
\begin{gathered}
S_{0}^{\prime}=x_{0} \\
S_{0}^{\prime \prime}=x_{0} \\
S_{t}^{\prime}=\alpha Y_{t}+(1-\alpha) S_{t-1}^{\prime} \\
S_{t}^{\prime \prime}=\alpha S_{t}^{\prime}+(1-\alpha) S_{t-1}^{\prime \prime}
\end{gathered}
$$

Then, the forecast for $Y_{t+k}$, for any $k>1$, is given by:

$$
F_{t+k}=L_{t}+k T_{t} \text {, }
$$

where $L_{t}$ is the estimated level at time $t$, and $T_{t}$ is the estimated trend at time $t$,

$$
\begin{gathered}
L_{t}=2 S_{t}^{\prime}-S_{t}^{\prime \prime} \\
T_{t}=\frac{\alpha}{1-\alpha}\left(S_{t}^{\prime}-S_{t}^{\prime \prime}\right)
\end{gathered}
$$

\section{BROWN's WeIGHTED ExPONENTIAL Moving AVERAGE (B-WEMA)}

The proposed method will be called as Brown's Weighted Exponential Moving Average (B-WEMA), since it's quite similar to the Weighted Exponential Moving Average (WEMA) method introduced by Hansun [14]. The main difference is on the methods been used. In [14], WEMA combine the Weighted Moving Average (WMA) and Exponential Moving Average (EMA) methods, while in this research we will combine the WMA with Brown's Double Exponential Smoothing, which is an improvement of EMA.

The algorithm's procedures of the proposed method can be written as follow:

1. Calculate the base value, $B_{t}$, using Eq. (1) for a given time series data and periods

2. Using the base value obtained, calculate the forecasting value using Eq. (2) - (6), whereas

$$
S_{t-1}^{\prime}=S_{t-1}^{\prime \prime}=B_{t}
$$

3. Return to step 1 until each data point in the time series data given ended.

\section{FORECAST ERROR MEASUREMENT}

To compare and measure the accuracy and robustness of the proposed method against other moving average method, we use two common measurement tools, i.e. Mean Square Error (MSE) and Mean Absolute Percentage Error (MAPE).

\section{A. Mean Square Error (MSE)}

Mean Square Error (MSE) denotes the average of the square of error sum between the forecasted data and the actual data. The formula can be written as follows [14],

$$
M S E=\frac{\sum_{t=1}^{n} e_{t}^{2}}{n}
$$

where $n$ denotes the number of data, $e_{t}$ denotes the forecasting error from $Y_{t}-\hat{Y}_{t}$. Here, $Y_{t}$ is the actual data and $\hat{Y}_{t}$ is the forecasted data.

\section{B. Mean Absolute Percentage Error (MAPE)}

Mean Absolute Percentage Error (MAPE) value gives us an indication about how much the average of absolute error of the forecasted data compare to the actual data, and denotes by the formula [14],

$$
M A P E=\frac{\sum_{t=1}^{n}\left|\frac{e_{t}}{Y_{t}}\right|}{n} \times 100
$$

where $n$ denotes the number of data, and $e_{t}$ denotes the forecasting error from $Y_{t}-\widehat{Y}_{t}$. The actual data is denoted by $Y_{t}$, while $\widehat{Y}_{t}$ denote the forecasted data.

\section{EXPERIMENTAL RESULTS AND ANALYSIS}

To test the accuracy and robustness of the proposed method, we will try to implement it in Jakarta Stock Exchange (JKSE) composite index data. The number of data been used were 100 JKSE data, taken monthly from April 2007 to July 2015 [17]. The length or span data (i.e. the specified number of data points to be used taken backward from the most recent data) and the initial data to start with can be chosen by the user. Mean Square Error (MSE) and Mean Absolute Percentage Error (MAPE) will be used to calculate and compare the accuracy and robustness of the proposed method against the other two moving average method, i.e. Weighted Moving Average (WMA) and Brown's Double Exponential Smoothing.

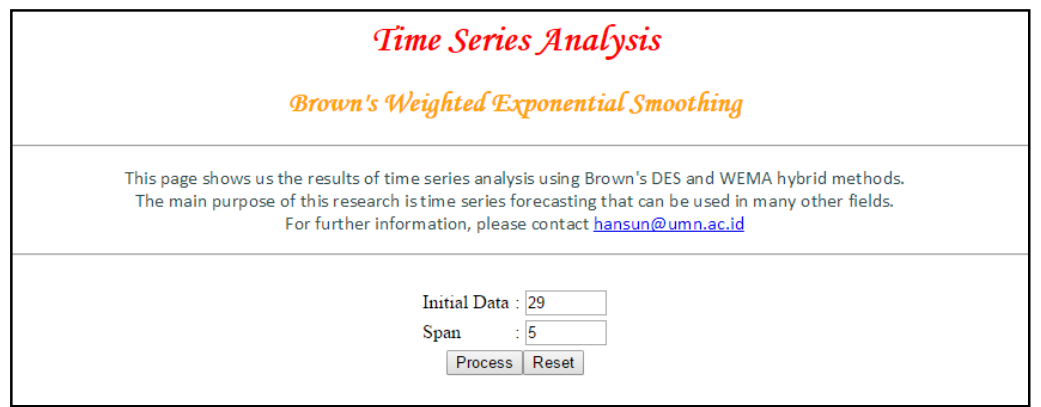

Fig.1. Interface of the system 
Fig. 1 shows the interface of the system. User can choose any value for the initial data to start with and span data as described above. As shown on Fig. 1, the initial data been used in this experiment is 29 and the span data been used is 5, which means that the calculation will be started from the 30th data period considering the last 5 data taken successively.

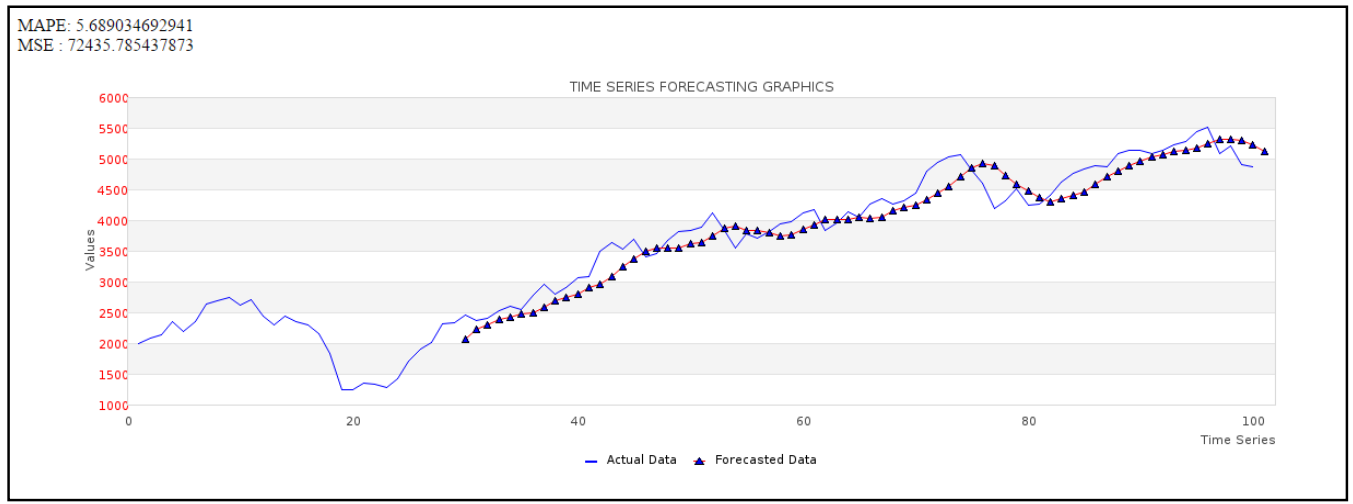

Fig.2. Weighted Moving Average Forecasting Results

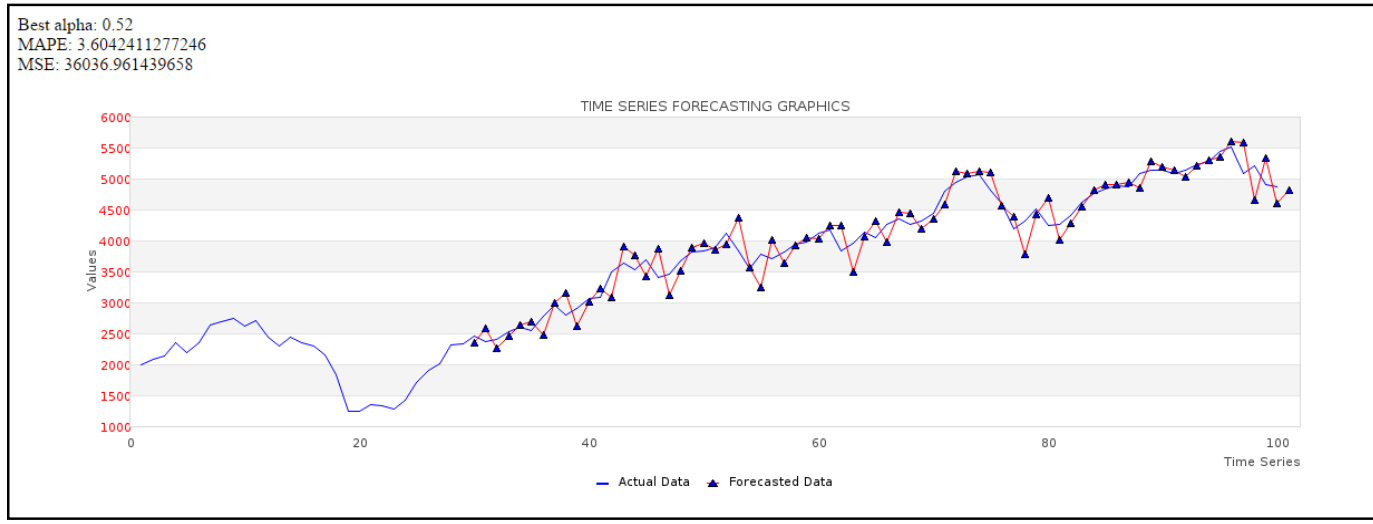

Fig.3. Brown's Double Exponential Smoothing Forecasting Results

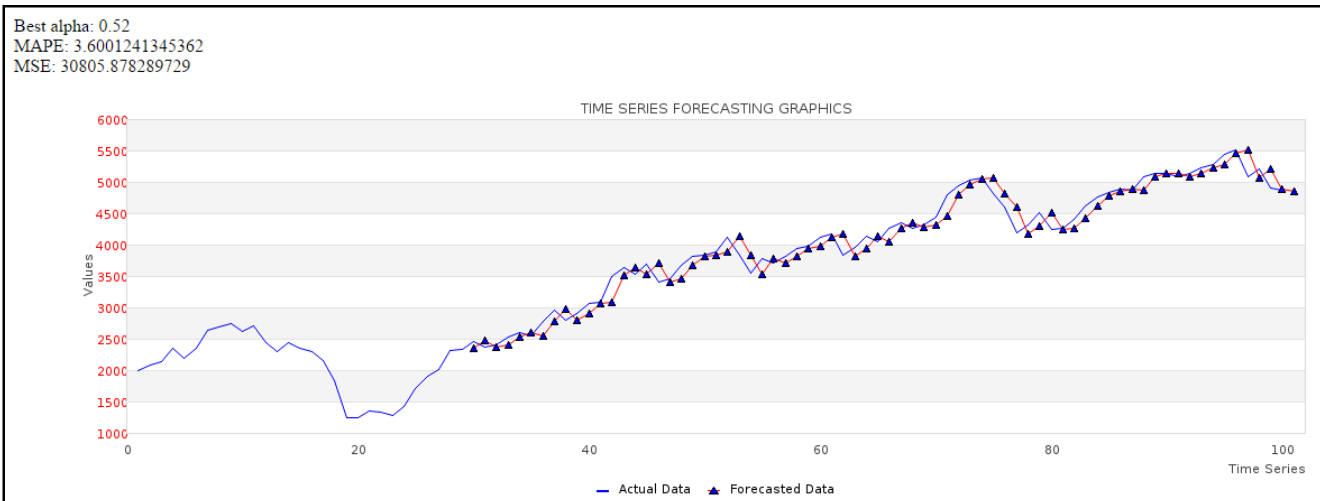

Fig.4. Brown's Weighted Exponential Moving Average Forecasting Results

The graph of forecasted data based on Weighted Moving Average (WMA), Brown's Double Exponential Smoothing (BDES), and Brown's Weighted Exponential Moving Average (B-WEMA) are shown on Fig. 2, Fig. 3, and Fig. 4 consecutively. On the figures, the actual data is denoted by the blue line, while the forecasted data is denoted by the red line with a triangle mark on each forecasted point.
TABLE I

MSE and MAPE values for each method

\begin{tabular}{|c|c|c|}
\hline MA method & MSE & MAPE \\
\hline WMA & 72435.785437873 & 5.689034692941 \\
\hline B-DES & 36036.961439658 & 3.6042411277246 \\
\hline B-WEMA & 30805.878289729 & 3.6001241345362 \\
\hline
\end{tabular}

Table 1 shows us the different MSE and MAPE values for each method. As can be seen, the MSE and MAPE values of the 
proposed method are the smallest among the other methods, which means that the proposed method can be used as a better forecasting tool in time series analysis.

\section{CONCLUSION}

In this paper, a new approach of moving average method has been introduced. The proposed method combines the basic formula of Weighted Moving Average (WMA) to get a base value, and then use it to get the forecasted value using Brown's Double Exponential Smoothing formula.

The experimental result on 100 Jakarta Stock Exchange (JKSE) composite index data shows a promising result. Compare to Weighted Moving Average and Brown's Double Exponential Smoothing, the proposed method excels in the accuracy and robustness of forecasted data, as can be seen from the small Mean Square Error (MSE) and Mean Absolute Percentage Error (MAPE) values.

As the future works, we can try to take a more comprehensive study to analyze the advantages and disadvantages of the proposed method compare to other hybrid moving average method, such as Weighted Exponential Moving Average (WEMA). Another study to combine other moving average methods, such as Holt-Winters Triple Exponential Smoothing can also be taken.

\section{REFERENCES}

[1] OECD: Glossary of Statistical Terms, https://stats.oecd.org/glossary/detail.asp?ID=2708, last accessed on August $19^{\text {th }}, 2015$.

[2] NIST/SEMATECH e-Handbook of Statistical Methods, http://www.itl.nist.gov/div898/handbook/pmc/section4/pmc41.htm, last accessed on August $19^{\text {th }}, 2015$.

[3] Subanar and Suhartono, Wavelet Neural Networks untuk Peramalan Data Time Series Finansial, Program Penelitian Ilmu Dasar Perguruan Tinggi, Yogyakarta: FMIPA UGM, 2009.

[4] Boediono and W. Koster, Teori dan Aplikasi Statistika dan Probabilitas, Bandung: PT. Remaja Rosdakarya, 2001.

[5] B. Render, R.M. Stair Jr., and M.E. Hanna, Quantitative Analysis for Management, $8^{\text {th }}$ ed., New Jersey: Pearson Education, Inc., 2003.

[6] M. Stevenson and J.E. Porter, "Fuzzy time series forecasting using percentage change as the universe of discourse," World Academy of Science, Engineering and Technology, vol. 27, no. 55, pp. 154-157, 2009.

[7] S. Hansun, "Peramalan data IHSG menggunakan fuzzy time series," Indonesian Journal of Computing and Cybernetic Systems (IJCCS), vol. 6, no. 2, pp. 79-88, July 2012.

[8] S. Hansun, "Jakarta stock exchange forecasting using backpropagation neural networks," Proc. of the 2013 IEEE International Conference on Electronics Technology and Industrial Development, October 2013.

[9] A. Popoola, S. Ahmad, and K. Ahmad, "A fuzzy-wavelet method for analyzing non-stationary time series," Proc. of the $5^{\text {th }}$ International Conference on Recent Advances in Soft Computing RASC2004, United Kingdom: Nottingham, 2004, pp. 231-236.

[10] A.O. Popoola, "Fuzzy-wavelet method for time series analysis," dissertation, Department of Computing, School of Electronics and Physical Sciences, Surrey: University of Surrey, 2007.

[11] C. Murphy, "Moving averages," http://www.investopedia.com/university/movingaverage/, last accessed on August $19^{\text {th }}, 2015$.

[12] S. Dash, "A comparative study of moving averages: simple, weighted, and exponential," http://www.tradestation.com/education/labs/analysisconcepts/a-comparative-study-of-moving-averages, last accessed on August $19^{\text {th }}, 2015$.

[13] N.E. Hwa, "Different uses of moving average (MA)," http://www.chartnexus.com/learning/static/pulses_apr2007.pdf, last accessed on August 19 ${ }^{\text {th }}, 2015$.

[14] S. Hansun, "A new approach of moving average method in time series analysis," Proc. of the 2013 IEEE International Conference on New Media, November 2013.

[15] incrediblecharts, "Weighted moving average", https://www.incrediblecharts.com/indicators/weighted_moving_average. php, last accessed on August $19^{\text {th }}, 2015$.

[16] R. Nau, "Moving average and exponential smoothing models", http://people.duke.edu/ rnau/411avg.htm, last accessed on August $19^{\text {th }}$, 2015.

[17] Yahoo! Finance, http://finance.yahoo.com/q/hp?s=\%5EJKSE $\& \mathrm{a}=03 \& \mathrm{~b}=1 \& \mathrm{c}=2007 \& \mathrm{~d}=06 \& \mathrm{e}=7 \& \mathrm{f}=2015 \& \mathrm{~g}=\mathrm{m}$, last accessed on July $20^{\text {th }}, 2015$.

\section{BIOGRAPHY}

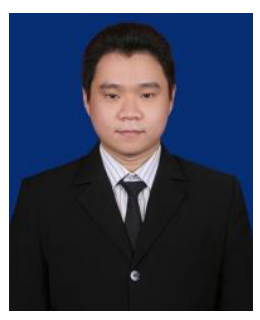

SENG HANSUN Tangerang, Indonesia. He received the S.Si. degree in Mathematics from Universitas Gadjah Mada, Yogyakarta, in 2008 and M.Cs. degrees in Computer Science from the same university, Universitas Gadjah Mada, Yogyakarta, in 2011.

Since 2011, he has been a Lecturer with the Computer Science Department, Universitas Multimedia Nusantara, Tangerang. He is the author of two books and 26 articles. His research interests include computational science, soft computing methods, internet and mobile technology. 